\title{
Prone positioning for patients with hypoxic respiratory failure related to COVID-19
}

\author{
Kevin Venus MD, Laveena Munshi MD MSc, Michael Fralick MD PhD
}

Cite as: CMAJ 2020 November 23;192:E1532-7. doi: 10.1503/cmaj.201201; early-released November 11, 2020

CMAJ Podcasts: author interview at www.cmaj.ca/lookup/doi/10.1503/cmaj.201201/tab-related-content

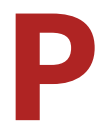

neumonia is the most common reason for admission to hospital among patients with coronavirus disease 2019 (COVID-19), and many such patients will require supplemental oxygen. ${ }^{1}$ Severe pneumonia can result in acute hypoxic respiratory failure necessitating supplemental oxygen therapy or respiratory support with mechanical ventilation. Severe acute respiratory failure may result in acute respiratory distress syndrome (ARDS) - a form of noncardiogenic pulmonary edema precipitated by a direct (e.g., pneumonia) or indirect (e.g., pancreatitis) injury. The mainstays of the management of ARDS are treating the underlying precipitant and supportive care, which includes mechanical ventilation with every effort to mitigate ventilatorassociated lung injury. Ventilation in the prone position is a technique that has been employed and evaluated over the past 3 decades among patients who are mechanically ventilated for all severities of ARDS, with the greatest benefits seen among those with moderate to severe ARDS, for which it is now considered standard of care. ${ }^{2}$

During the COVID-19 pandemic, as health care systems scrambled to accommodate the surge in patients with acute respiratory failure, reports emerged of the potential benefit of prone positioning of patients with COVID-19 who were hypoxic and not intubated. ${ }^{1}$ The findings of several observational studies suggested that prone positioning may improve oxygenation among patients on both low-flow (e.g., nasal prong oxygen) and higherflow oxygen delivery devices (e.g., high-flow nasal cannula) not yet receiving mechanical ventilation. ${ }^{1,3-7}$ We discuss prone positioning, its physiologic mechanisms, who may be eligible to receive it, accumulating evidence related to its effectiveness among patients with hypoxic respiratory failure related to COVID-19 pneumonia and potential harms of the procedure. By summarizing the available literature available to guide clinicians in the use of prone positioning for this population (Box 1), we also draw attention to important areas of future investigation.

\section{Box 1: Evidence used in this review}

We conducted a MEDLINE search of all English-language articles published between Jan. 1, 2020, and Sept. 14, 2020, for the words or phrases "prone position" or "prone positioning" in the context of the treatment of coronavirus disease 2019 (COVID-19).

\section{KEY POINTS}

- Prone positioning has been widely adopted into standard practice for patients with severe acute respiratory distress syndrome who are mechanically ventilated based on highquality evidence.

- Prone positioning in patients with hypoxic respiratory failure who are awake, spontaneously breathing and not intubated is possible in noncritical care settings; evidence has emerged of its use in the management of patients with coronavirus disease 2019 (COVID-19) pneumonia, showing potential for improved oxygenation and decreased dyspnea.

- Studies have not yet provided clinicians with tools to predict which patients with COVID-19 are most likely to improve with prone positioning, nor have they proven whether prone positioning is able to delay or avoid the need for invasive ventilation or shown a mortality benefit.

- Prone positioning for patients who are mechanically ventilated comes with risks related to dislodgement of endotracheal tubes and access lines, which are reduced for awake, nonventilated patients; however, risks related to pressure may be mitigated as patients who are awake can change position independently.

- Randomized controlled trials are needed to better understand the benefits and adverse effects of prone positioning in patients with COVID-19 who are breathing spontaneously.

\section{What is prone positioning and how does it affect lung function?}

In the setting of severe ARDS, ventilation in the supine position results in gravitational forces that may increase pulmonary edema and atelectasis in dependent (posterior) lung zones. Abdominal organs displace the posterior diaphragm superiorly, exacerbating posterior lung collapse. ${ }^{8}$ Defective hypoxic pulmonary vasoconstriction may also contribute to ventilation/ perfusion (V/Q) mismatch. ${ }^{9}$

Prone positioning refers to positioning a patient face down onto their anterior chest and abdomen to take advantage of physiologic changes that can result in improved oxygenation through decreased V/Q mismatch and, potentially, decreased lung injury. In the prone position, expansion of the anterior chest wall is restricted, resulting in a more homogeneous chest wall 
compliance (Figure 1), and gravitational forces on lung parenchyma enable greater recruitment of the posterior zones, allowing for a greater proportion of alveoli to participate in gas exchange. A more equal distribution of stress forces onto the lungs by the diaphragm also occurs in the prone position, which may help reduce lung injury both during mechanical ventilation and while breathing spontaneously. ${ }^{8,10}$ The position also enhances the inferior movement of the diaphragm, which relieves compression on atelectatic posterior lung zones,

\section{Supine position}

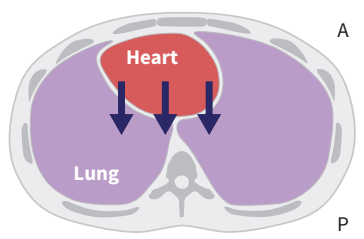

Gravitational pressure of heart and mediastinum on the lungs.

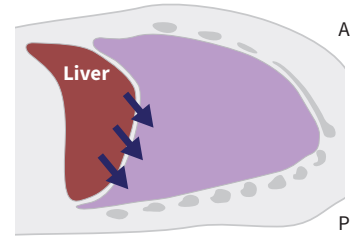

Compressive effects of the abdominal organs on the lungs.

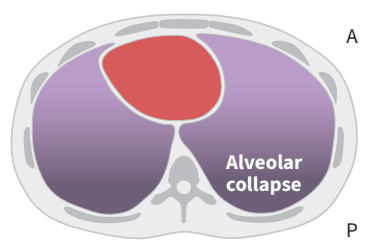

Expansion of the chest wall and overall less homogeneous chest wall compliance.

\section{Prone position}

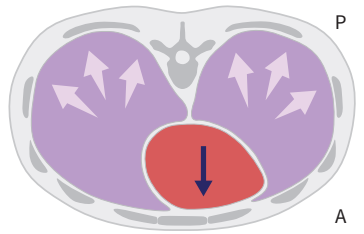

Decreased gravitational pressure of heart and mediastinum on the lungs.

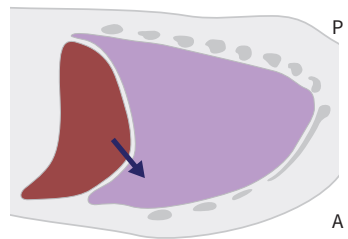

Decreased compressive effects of the abdominal organs on the lungs.

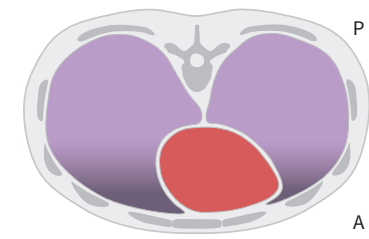

More homogeneous chest wall compliance due to restriction of anterior chest wall movement.
Figure 1: A comparison of some physiological effects of supine (left) and prone (right) positioning. In the prone position, reduced force from other organs is applied to the lungs, which allows for improved lung compliance and therefore improved relation between ventilation and perfusion of the lungs. Top panel: Dark blue arrows indicate the direction of the force exerted on the lungs by the heart. Middle panel: Arrows indicate the direction of the force exerted on the lungs by the abdominal organs. For prone positioning, less force from these organs is applied to the lungs, which allows for improved lung compliance by decreasing the force it needs to expand against. Bottom panel: Graded shading represents lung perfusion with darker shade representing greater ventilation/perfusion mismatch owing to alveolar collapse posteriorly in the supine position (reduced in the prone patient as this position allows for more even chest expansion). Note: $\mathrm{A}=$ anterior, $\mathrm{P}=$ posterior. Modified from the original figure created by Mike Fralick and Saba Manzoor by Émilie Lacharité. increasing lung recruitability. ${ }^{10,11}$ Prone positioning has relatively little effect on a patient's lung perfusion, however, as most blood flow is directed to posterior lung zones while both supine and prone. ${ }^{9}$ The result is improved V/Q matching, a decrease in the shunt fraction and improved oxygenation.

\section{How should patients be placed in the prone position?}

Turning a patient with an endotracheal tube and other indwelling devices from the supine to prone position is a process that must be managed meticulously. Because most patients are heavily sedated and usually medically paralyzed to facilitate ventilation, 3 or more trained staff are needed to turn the patient in a coordinated fashion. ${ }^{12}$

During the COVID-19 pandemic, some institutions have attempted prone positioning among patients with hypoxia who are awake and not intubated, either in the emergency department or inpatient units. For patients who are not intubated, many of the risks associated with placement in the prone position are mitigated (e.g., displacement of an endotracheal tube). The process is easier if patients can turn without physical assistance; however, especially for the initial episode of prone positioning, a staff member should be present to ensure that connection of oxygen tubing, intravenous lines and any other tubing (e.g., Foley catheter) are maintained during repositioning. Access to continuous oxygen plethysmography and close monitoring of the respiratory rate is advantageous to ensure that the patient does not deteriorate clinically and to facilitate the monitoring of respiratory status among patients enrolled in research studies.

Appropriate cushioning with pillows or rolled blankets under pressure points, such as the patient's upper chest and pelvis, can increase comfort and tolerability of the prone position, and potentially mitigate increased intra-abdominal pressure that can transfer to the lungs. Patients who are breathing spontaneously can alter their head and arm position at least every 2 hours to avoid pressure injuries. ${ }^{12}$

\section{Who is eligible for prone positioning?}

Before the COVID-19 pandemic, prone positioning was used mainly for patients with severe ARDS who were being ventilated mechanically. ${ }^{13}$ Among patients with COVID-19 who are breathing spontaneously and not intubated, observational data suggest that prone positioning might improve oxygenation in those who can tolerate the position. Several randomized controlled trials (RCTs) are underway to investigate the effectiveness of prone positioning in both patients requiring low-flow supplemental oxygen in a ward-based setting (Clinical Trials nos. NCT04383613, NCT04402879, NCT04517123) and patients with more severe respiratory failure that requires higher-flow oxygen support (Clinical Trials nos. NCT04350723, NCT04543760).

Placement in the prone position should be avoided for patients who are breathing spontaneously but may require imminent intubation (e.g., those with a reduced level of consciousness or worsening hypoxia despite maximal supplemental oxygen) or 
those with anatomic contraindications to prone positioning as identified by the established ARDS literature (e.g., facial trauma; recent abdominal, thoracic or spine surgery; recent pacemaker insertion; or unstable spine or pelvic fractures). ${ }^{1,4,12,14}$

Little is known about the effects of prone positioning during pregnancy on the fetus, as pregnant patients are frequently excluded from trials (a practice recently challenged during the COVID-19 pandemic ${ }^{15}$ ), although a previous case report described successful prone positioning for a pregnant patient who was critically ill with viral pneumonia. ${ }^{16} \mathrm{~A}$ protocol and guide for prone positioning based on expert opinion was recently developed for clinicians caring for obstetrical patients, ${ }^{17}$ and successful use of prone positioning for a pregnant patient with COVID-19 has been documented in a case report. ${ }^{18}$

\section{For whom is prone positioning effective?}

\section{Patients with ARDS}

Prone positioning has been evaluated since the 1970s as part of the management of patients with ARDS. ${ }^{13}$ Among patients with moderate-to-severe ARDS, prolonged prone positioning (at least $12 \mathrm{~h} / \mathrm{d}$ ) has been found to reduce mortality and is now the standard of care in the management of these patients. ${ }^{2,13}$ Ventilation in the prone position is thought to decrease ventilatorassociated lung injury through greater uniformity in the distribution of tidal volume, which leads to less nonphysiologic strain on the lungs. A large multicentre RCT published in 2013 involving 474 participants in France found that ventilation of patients with moderate-to-severe ARDS (arterial partial pressure of oxygen/ fractional concentration of oxygen in inspired air $\left[\mathrm{PaO}_{2} / \mathrm{FiO}_{2}\right]$ $<150 \mathrm{~mm} \mathrm{Hg}$ ) who were placed in the prone position for 16 hours per day was associated with an improved 28-day mortality compared with being positioned in the supine position (hazard ratio $0.39,95 \%$ confidence interval $[\mathrm{Cl}] 0.25-0.63) .{ }^{12} \mathrm{~A}$ meta-analysis of 8 RCTs that pooled data across 2129 patients with ARDS who were mechanically ventilated subsequently showed that patients with moderate-to-severe ARDS who were randomly assigned to prone positioning for at least 12 hours per day had a lower mortality rate (risk ratio $[\mathrm{RR}] 0.74,95 \% \mathrm{Cl} 0.56-0.99$ ) than those ventilated in the supine position. ${ }^{13}$

Prone positioning has been attempted in patients with ARDS related to COVID-19 and, although there is debate about whether there are unique physiologic attributes associated with ARDS related to COVID-19,,$^{19,20}$ some guidelines (e.g., Surviving Sepsis Campaign) recommend that prone positioning be considered for patients with severe ARDS related to COVID-19 because prone positioning is known to be beneficial in the setting of severe ARDS. ${ }^{21-23}$

\section{Patients who are not intubated}

Before the COVID-19 pandemic, prone positioning was infrequently used in the management of patients with hypoxic respiratory failure who were not intubated. A 2015 single-centre retrospective cohort study evaluated the response of 15 patients who received a total of 43 prone-positioning procedures. Most participants $(n=13)$ had a diagnosis of pneumonia and, during $42 \%$ of the procedures, noninvasive ventilation was used. Partici- pants' hypoxia significantly improved while prone (supine $\mathrm{PaO}_{2} / \mathrm{FiO}_{2}$ mean 127 [standard deviation (SD) 49] mm Hg, prone $\mathrm{PaO}_{2} / \mathrm{Fio}_{2}$ mean 186 [SD 72] mm Hg; $p<0.05)$, although there was no sustained improvement when patients were returned to the supine position. ${ }^{7}$

A multicentre prospective cohort study examined the effect of combining prone positioning with either noninvasive ventilation or high-flow nasal cannula in 20 participants who were awake, 11 of whom had viral pneumonia. ${ }^{4} \mathrm{~A}$ stepwise approach was used to add prone positioning to either an oxygen-delivery system based on clinical response of the patient or to switch between noninvasive ventilation and high-flow nasal cannula. Baseline hypoxia in patients was not reported, although all patients met the criteria for ARDS. The authors found improved oxygenation when prone positioning was added to high-flow nasal cannula but not to noninvasive ventilation and, although 11 participants avoided intubation, the study found a nonsignificant increase in patients with severe ARDS who required intubation and mechanical ventilation. ${ }^{4}$

The literature to guide the use of prone positioning in patients with acute respiratory failure related to COVID-19 who are breathing spontaneously and not intubated comprises case reports, case series and observational studies. ${ }^{1,3,4,6,7,14}$ The large number of patients with COVID-19 worldwide has led to the evaluation of prone positioning outside of the intensive care unit (ICU): in emergency departments, medical wards and repurposed surgical floors.

Based on the available observational evidence (summarized in Table 1), prone positioning in this patient population appears to improve oxygenation for many patients. ${ }^{1,3,6,7,28-32}$ For example, one prospective nonrandomized study involving 50 patients who received prone positioning in the emergency department showed improved oxygenation within 5 minutes of placement, although $36 \%$ required intubation within about 72 hours. ${ }^{6}$ Noninvasive ventilation and prone positioning were used concurrently in one small cross-sectional study involving 15 participants with COVID19 and were shown to improve oxygenation, including $80 \%$ of participants who had sustained improvement after being returned to the supine position. ${ }^{3} \mathrm{~A}$ retrospective cohort study reviewed the outcomes for 24 patients in a respiratory unit who received continuous positive airway pressure (CPAP) in conjunction with prone positioning and found that, although addition of CPAP did not significantly increase arterial oxygen saturation, the combination of CPAP and prone positioning did (mean arterial oxygen saturation at baseline $94 \%$ (SD 3\%) and after prone positioning 96\% (SD 2\%; $p<0.05) .{ }^{25}$ This improvement was sustained 1 hour after participants were returned to the supine position. ${ }^{25} \mathrm{~A}$ prospective cohort study involving 56 patients who received prone positioning in either the emergency department, medical ward or monitored unit ${ }^{24}$ showed that prone positioning was feasible in $84 \%$ of participants and improved oxygenation significantly, although this did not persist when patients were returned to the supine position. In a small, prospective single-centre study in France, use of a single episode of prone positioning was shown to have good tolerability but improved oxygenation for only $25 \%$ of participants, with half of those who responded showing persistent improvement. ${ }^{1}$ However, lack of randomization in these studies means that the benefits observed may be because of prone positioning, selection bias or confounding by indication. 
Table 1: Summary of evidence for prone positioning in patients with coronavirus disease 2019 who are not intubated

\begin{tabular}{|c|c|c|c|c|c|c|c|}
\hline Study & $\begin{array}{l}\text { Study } \\
\text { design }\end{array}$ & Study population & $\begin{array}{c}\text { Primary } \\
\text { outcome(s) }\end{array}$ & Location & $\begin{array}{l}\text { Oxygen } \\
\text { support }\end{array}$ & $\begin{array}{l}\text { Prone } \\
\text { protocol }\end{array}$ & Main finding(s) \\
\hline $\begin{array}{l}\text { Caputo et } \\
\text { al. }^{6}\end{array}$ & $\begin{array}{l}\text { Single- } \\
\text { centre } \\
\text { prospective } \\
\text { cohort study }\end{array}$ & $\begin{array}{l}n=50 \\
\text { Baseline } \mathrm{SpO}_{2} \text { before } \\
\text { PP: median } 84 \% \text { (IQR } \\
75 \%-90 \%)\end{array}$ & $\begin{array}{l}\text { Change in } \\
\text { oxygenation } \\
\left(\mathrm{SpO}_{2}\right) \text {, rate of } \\
\text { intubation in first } \\
24 \mathrm{~h} \text { of } \\
\text { presentation to ED }\end{array}$ & ED & $\begin{array}{l}\text { NRB ( } 38 \text { of } \\
50 \text { patients, } \\
76 \% \text { ) or HFNC } \\
\text { (12 of } \\
50 \text { patients, } \\
24 \%)\end{array}$ & $\begin{array}{l}\text { Five minutes of } \\
\text { PP without } \\
\text { change in } \\
\text { oxygen delivery }\end{array}$ & $\begin{array}{l}\text { - } \mathrm{SpO}_{2} \text { after a single episode } \\
\text { of } 5 \text { min PP: median } 94 \% \\
\text { (IQR } 90 \%-95 \%) \\
\text { - Eighteen of } 50 \text { patients } \\
\text { ( } 36 \% \text { ) intubated within } \\
\text { about } 72 \mathrm{~h} \text { of presentation }\end{array}$ \\
\hline $\begin{array}{l}\text { Elharrar et } \\
\text { al. }^{1}\end{array}$ & $\begin{array}{l}\text { Prospective } \\
\text { before-after } \\
\text { study, single } \\
\text { centre }\end{array}$ & $\begin{array}{l}n=24 \\
\text { Baseline } \mathrm{PaO}_{2}: \text { mean } \\
72.8 \text { (SD 14.2) } \mathrm{mm} \mathrm{Hg}\end{array}$ & $\begin{array}{l}\text { Increase in } \mathrm{PaO}_{2} \geq \\
20 \% \text { of baseline }\end{array}$ & $\begin{array}{l}\text { Medical } \\
\text { ward }\end{array}$ & $\begin{array}{l}16 \text { of } 24 \\
\text { patients ( } 67 \%) \\
\text { on } \mathrm{NC}<4 \mathrm{~L} / \\
\text { min; } 8 \text { of } 25 \\
\text { patients ( } 33 \%) \\
\text { on } \mathrm{NC} \geq 4 \mathrm{~L} / \\
\text { min or HFNC }\end{array}$ & $\begin{array}{l}\text { Single episode } \\
\text { of PP; duration } \\
\text { determined by } \\
\text { comfort }\end{array}$ & $\begin{array}{l}\text { - Six of } 24 \text { patients }(25 \%) \\
\text { had the primary outcome } \\
\text { - No persistent response to } \\
\text { PP once in supine position } \\
\text { again } \\
\text { - Fifteen of } 24 \text { patients } \\
(63 \%) \text { able to tolerate PP } \\
\text { for }>3 \mathrm{~h}\end{array}$ \\
\hline $\begin{array}{l}\text { Sartini et } \\
\text { al. }^{3}\end{array}$ & $\begin{array}{l}\text { Single- } \\
\text { centre } \\
\text { cross- } \\
\text { sectional } \\
\text { study }\end{array}$ & $\begin{array}{l}n=15 \\
\text { Baseline } \mathrm{PaO}_{2} / \mathrm{FiO}_{2} \text { : } \\
\text { mean } \\
157 \text { (SD 43) mm Hg }\end{array}$ & $\begin{array}{l}\text { Change in } \\
\text { oxygenation and } \\
\text { respiratory vital } \\
\text { signs }\end{array}$ & $\begin{array}{l}\text { Medical } \\
\text { ward }\end{array}$ & NIV & $\begin{array}{l}\text { Cycles of PP: } \\
\text { median } 2 \text { (IQR } \\
\text { 1-3) for a } \\
\text { median } \\
\text { duration of } \\
3 \text { (IQR 1-6) h }\end{array}$ & $\begin{array}{l}\text { - All patients had } \\
\text { improvement in RR, } \mathrm{PaO}_{2} / \\
\mathrm{FlO}_{2} \text { during } \mathrm{PP}^{\star} \\
\text { - Twelve of } 15 \text { patients } \\
\text { (80\%) had improvement in } \\
\text { oxygenation after } \mathrm{PP}^{\star} \\
\text { - Eleven of } 15 \text { patients }(73 \%) \\
\text { had improvement in } \\
\text { comfort during PP }\end{array}$ \\
\hline $\begin{array}{l}\text { Coppo et } \\
\text { al. }^{24}\end{array}$ & $\begin{array}{l}\text { Single- } \\
\text { centre } \\
\text { prospective } \\
\text { cohort study }\end{array}$ & $\begin{array}{l}n=56 \\
\text { Baseline } \mathrm{PaO}_{2} / \mathrm{FiO}_{2} \text { : } \\
\text { mean } 180.5 \\
(\mathrm{SD} 76.6) \mathrm{mm} \mathrm{Hg}\end{array}$ & $\begin{array}{l}\text { Change in supine } \\
\mathrm{PaO}_{2} / \mathrm{FiO}_{2} \text { after } \\
\text { episode of PP }\end{array}$ & $\begin{array}{l}\text { Medical } \\
\text { ward, ED, } \\
\text { HDU }\end{array}$ & $\begin{array}{l}\text { CPAP ( } 44 \text { of } \\
56 \text { patients, } \\
79 \%), \\
\text { reservoir mask } \\
\text { ( } 9 \text { of } 56 \\
\text { patients, } \\
16 \%) \text {, Venturi } \\
\text { mask ( } 3 \text { of } 56 \\
\text { patients, } 5 \%)\end{array}$ & $\begin{array}{l}\text { Minimum } 3 \mathrm{~h} \text {, } \\
\text { up to } 8 \mathrm{~h} \\
\text { depending on } \\
\text { comfort; } \\
25 \text { patients } \\
\text { maintained > } \\
3 \mathrm{~h}\end{array}$ & $\begin{array}{l}\text { - Improved oxygenation } \\
\text { while in PP: mean } \mathrm{PaO}_{2} / \\
\mathrm{FiO}_{2} 285.5 \text { (SD 112.9) } \\
\text { - Nonsignificant } \\
\text { improvement in } \\
\text { oxygenation after PP in } \\
50 \% \text { of participants }\end{array}$ \\
\hline $\begin{array}{l}\text { Winearls et } \\
\text { al. }{ }^{25}\end{array}$ & $\begin{array}{l}\text { Single- } \\
\text { centre } \\
\text { retrospective } \\
\text { cohort study }\end{array}$ & $\begin{array}{l}n=24 \\
\text { Baseline } \mathrm{PaO}_{2} / \mathrm{FiO}_{2} \text { on } \\
\text { CPAP: mean } 143 \\
\text { (SD 73) } \mathrm{mm} \mathrm{Hg}\end{array}$ & $\begin{array}{l}\text { Change in } \\
\text { respiratory vital } \\
\text { signs, tolerance } \\
\text { and duration of PP }\end{array}$ & HDU & CPAP & $\begin{array}{l}\text { PP initiated } \\
\text { median } 30 \text { (IQR } \\
7-99) \text { h after } \\
\text { CPAP; } \\
\text { mean duration } \\
\text { of PP in first } \\
24 \mathrm{~h}: 8 \text { (SD 5) h, } \\
\text { continued for } 10 \\
\text { (SD 5) d }\end{array}$ & $\begin{array}{l}\text { - Significant increase in } \\
\mathrm{PaO}_{2} / \mathrm{FiO}_{2} \text { with PP and } \\
\mathrm{CPAP} \text { : mean } 252 \\
\text { (SD } 87) \mathrm{mm} \mathrm{Hg}, p<0.01 \text {; } \\
\text { increase sustained } 1 \mathrm{~h} \\
\text { after PP stopped } \\
\text { - Two patients not able to } \\
\text { tolerate PP because of } \\
\text { discomfort }\end{array}$ \\
\hline $\begin{array}{l}\text { Solverson } \\
\text { et al. }{ }^{26}\end{array}$ & $\begin{array}{l}\text { Multicentre } \\
\text { retrospective } \\
\text { cohort study }\end{array}$ & $\begin{array}{l}n=17 \\
\text { Baseline } \mathrm{PaO}_{2} / \mathrm{FiO}_{2} \text { : } \\
\text { median } 152(\mathrm{IQR} \\
\text { 97-233) } \mathrm{mm} \mathrm{Hg}\end{array}$ & $\begin{array}{l}\text { Tolerance of PP, } \\
\text { physiologic and } \\
\text { clinical outcomes }\end{array}$ & $\begin{array}{l}\text { Medical } \\
\text { ward, ICU }\end{array}$ & $\begin{array}{l}\text { NC, NRB, } \\
\text { HFNC }\end{array}$ & $\begin{array}{l}\text { Median no. of } \\
\text { daily PP } \\
\text { sessions } 2 \text { (IQR } \\
\text { 1-6) with a } \\
\text { median } \\
\text { duration of } 75 \\
\text { (IQR 30- } \\
\text { 480) min for first } \\
\text { session }\end{array}$ & $\begin{array}{l}\text { - Decreased respiratory rate } \\
\text { and improved oxygenation } \\
\text { while in PP } \\
\text { - } 35 \%(n=6) \text { of patients } \\
\text { stopped PP after } \leq 60 \text { min } \\
\text { because of } \\
\text { musculoskeletal pain or } \\
\text { general discomfort }\end{array}$ \\
\hline $\begin{array}{l}\text { Ferrando et } \\
\text { al. }^{27}\end{array}$ & $\begin{array}{l}\text { Multicentre } \\
\text { prospective } \\
\text { cohort study }\end{array}$ & $\begin{array}{l}n=199 ; 144 \text { patients } \\
\text { received only HFNC } \\
\text { and } 55 \text { received } \\
\text { HFNC + PP }\end{array}$ & $\begin{array}{l}\text { Physiologic and } \\
\text { clinical outcomes, } \\
\text { including } \\
\text { intubation risk }\end{array}$ & ICU & HFNC & $\begin{array}{l}\text { PP was } \\
\text { considered only } \\
\text { if duration was } \\
>16 \mathrm{~h} / \mathrm{d} \text {, } \\
\text { regardless of } \\
\text { the no. of } \\
\text { sessions }\end{array}$ & $\begin{array}{l}\text { - Significant increase in } \\
\mathrm{PaO}_{2} / \mathrm{FiO}_{2} \text { for combination } \\
\text { of } \mathrm{HFNC}+\mathrm{PP} \\
\text { - Trend toward delay in } \\
\text { intubation for patients } \\
\text { receiving HFNC + PP; no } \\
\text { difference in intubation } \\
\text { rates between groups }\end{array}$ \\
\hline
\end{tabular}

Note: $\mathrm{CPAP}=$ continuous positive airway pressure, $\mathrm{ED}=$ emergency department, $\mathrm{FiO}_{2}=$ fractional concentration of oxygen in inspired air, $\mathrm{HDU}=$ high dependency unit, $\mathrm{HFNC}=$ high-flow nasal cannula, ICU = intensive care unit, IQR = interquartile range, $\mathrm{NC}=$ nasal cannula, $\mathrm{NIV}=$ noninvasive ventilation, $\mathrm{NRB}=$ nonrebreather high-flow oxygen mask, $\mathrm{PaO}{ }_{2}=$ arterial partial pressure of oxygen, $\mathrm{PP}=$ prone positioning, $\mathrm{RR}=$ respiratory rate, $\mathrm{SD}=$ standard deviation, $\mathrm{SpO}_{2}=$ peripheral oxygen saturation of hemoglobin

*Exact data not available. 
Evidence that prone positioning decreases the need for intubation is lacking. Some observational studies have shown that prone positioning results in a decreased respiratory rate, ${ }^{3,28}$ which may lessen patients' risk of developing self-inflicted lung injury, ${ }^{3,10}$ although extrapolating from this surrogate outcome should be done with caution. ${ }^{1,3,6,7}$ Among patients with mild or moderate ARDS who were intubated or received short $(<12 \mathrm{~h}$ daily) durations of prone positioning, improved oxygenation did not correlate with a mortality benefit. ${ }^{13}$ Furthermore, evidence about the persistence of improvement in oxygenation once patients who are spontaneously breathing return to the supine position is not consistent, ${ }^{1,3,6,11,24,25,28}$ which suggests that RCTs that examine clinical outcomes among patients with COVID-19 who receive prone positioning are needed. Despite these deficiencies in evidence, the Intensive Care Society in the United Kingdom has released guidance based on expert opinion that encourages the use of prone positioning for patients who are not intubated because of its ease of application and potential benefits. ${ }^{33}$

\section{What are the potential harms of prone positioning?}

Among patients with ARDS who are mechanically ventilated, potential adverse events from prone positioning arise mostly when turning patients to the prone position (owing to tube or line dislodgment) and from sequalae of prolonged static positioning in patients who are unable to move (including pressure wounds, pressure neuropathy or neurapraxia and facial edema). ${ }^{13}$ Most of these risks are substantially reduced in patients who are spontaneously breathing and not intubated because they are able to shift position as required for comfort.

Although patient discomfort can be a limiting factor in the use of prone positioning or can lead to its early cessation, proper positioning and cushioning of pressure points may lead to better tolerance. ${ }^{1,4,7,11,31} \mathrm{~A}$ Canadian prospective cohort study involving 4 hospitals in Calgary evaluated the safety and tolerability of prone positioning of patients who were not intubated on both the medical ward and in the ICU. ${ }^{26}$ The study reported that 17 participants received a median of 2 (range 1-6) sessions of prone positioning for a median of 75 (range 30-480) minutes. Time spent prone was limited by back or shoulder pain $(n=2,12 \%)$, general discomfort $(n=6$, $35 \%)$ and delirium $(n=1,6 \%)$. Eight patients $(47 \%)$ had no tolerability problems. There were otherwise no serious adverse events. ${ }^{26}$

Whether prolonged prone positioning in patients with COVID19 who are awake and not intubated increases the risk for venous thromboembolic disease is an important consideration, because observational studies have shown COVID-19 to be associated with an increased risk of venous thrombosis. ${ }^{34}$ The published studies of prone positioning in nonintubated patients have sparsely reported on its harms.

If prone positioning delays rather than prevents intubation, it may increase rates of emergent intubation, which carries its own risks. A 2020 multicentre cohort study across 36 hospitals in Spain and Andorra found that use of prone positioning with high-flow nasal cannula did not reduce the risk of intubation (RR 1.002, 95\% Cl 0.531-1.890; $p=0.99) .{ }^{27}$ This study also showed a nonsignificant trend of increasing time to intubation ( 2.0 v. $4.1 \mathrm{~d}, p=0.054)$, which raises concern for potential harm caused by delayed intubation. ${ }^{27}$

\section{What questions remain?}

Studies have not yet provided clinicians with tools to predict which patients are most likely to improve; characterized the relative benefits of prone positioning, high-flow nasal cannula and noninvasive intubation (both independently and when combined); determined the optimal "dose" of prone positioning; or, most critically, proven whether prone positioning is able to delay or avoid the need for invasive ventilation. It is not known whether prone positioning can reduce health care costs because studies of its cost-effectiveness are lacking. Although it appears that prone positioning can be implemented outside of critical care settings with minimal cost, it may be associated with increased use of personal protective equipment (PPE) if several health care workers need to assist with prone positioning. However, if the intervention is shown in future studies to decrease admissions to critical care units, this could translate into substantial cost savings. Even if mechanical ventilation is delayed or avoided, this may not lead to improved patient outcomes; therefore, identifying patients who are not likely to benefit from a trial of nonintubated prone positioning will be crucial. Rigorous RCTs will be essential in addressing these questions.

\section{What are the logistical considerations for using prone positioning during the COVID-19 pandemic?}

Prone positioning of patients with COVID-19 on medical wards may become a more common practice in an effort to prevent mechanical ventilation if critical care resources become overwhelmed. As modelling studies have indicated this may be a risk for Canadian hospitals if public interventions are not followed, ${ }^{35,36}$ hospitals should therefore develop or adopt guidance on prone positioning and support rapid knowledge translation and training of clinical staff. As an example, Doussot and colleagues described the creation of a dedicated prone-positioning team at a regional hospital in France. ${ }^{37}$ Surgeons, nurses, physiotherapists and other clinicians volunteered to receive training that included incorporation of a checklist, simulation and proper PPE education. ${ }^{37}$

\section{Conclusion}

Prone positioning has been widely adopted into standard practice for patients with severe ARDS who are mechanically ventilated based on robust RCT evidence. However, since the COVID-19 pandemic has overwhelmed some health systems around the globe, leading to intensive care resources becoming strained, prone positioning for patients who are breathing spontaneously and not intubated is an attractive intervention because of its easy administration in many care settings and sound physiologic rationale. Although the current evidence base to support the use of prone positioning is of low quality, many RCTs are currently underway that are likely to provide answers to questions regarding its clinical benefit, safety profile and possible cost-effectiveness. Good evidence to guide patient selection and timing of starting and stopping prone positioning is needed. 


\section{References}

1. Elharrar X, Trigui Y, Dols A-M, et al. Use of prone positioning in nonintubated patients with COVID-19 and hypoxemic acute respiratory failure. JAMA 2020;323:2336-8.

2. Fan E, Del Sorbo L, Goligher EC, et al.; American Thoracic Society; European Society of Intensive Care Medicine; Society of Critical Care Medicine. An official American Thoracic Society/European Society of Intensive Care Medicine/Society of Critical Care Medicine clinical practice guideline: mechanical ventilation in adult patients with acute respiratory distress syndrome [published erratum in Am J Respir Crit Care Med 2017;195:1540]. Am J Respir Crit Care Med 2017;195:1253-63.

3. Sartini C, Tresoldi M, Scarpellini P, et al. Respiratory parameters in patients with COVID-19 after using noninvasive ventilation in the prone position outside the intensive care unit. JAMA 2020;323:2338-40.

4. Ding L, Wang L, Ma W, et al. Efficacy and safety of early prone positioning combined with HFNC or NIV in moderate to severe ARDS: a multi-center prospective cohort study. Crit Care 2020;24:28.

5. Sun Q, Qiu H, Huang M, et al. Lower mortality of COVID-19 by early recognition and intervention: experience from Jiangsu Province. Ann Intensive Care 2020;10:33.

6. Caputo ND, Strayer RJ, Levitan R. Early self-proning in awake, non-intubated patients in the emergency department: a single ED's experience during the COVID-19 pandemic. Acad Emerg Med 2020;27:375-8.

7. Scaravilli V, Grasselli G, Castagna L, et al. Prone positioning improves oxygenation in spontaneously breathing nonintubated patients with hypoxemic acute respiratory failure: a retrospective study. J Crit Care 2015;30:1390-4.

8. Scholten EL, Beitler JR, Prisk GK, et al. Treatment of ARDS with prone positioning. Chest 2017;151:215-24.

9. Pappert D, Rossaint R, Slama K, et al. Influence of positioning on ventilationperfusion relationships in severe adult respiratory distress syndrome. Chest 1994;106:1511-6.

10. Telias I, Katira BH, Brochard L. Is the prone position helpful during spontaneous breathing in patients with COVID-19? JAMA 2020;323:2265-7.

11. Slessarev M, Cheng J, Ondrejicka M, et al. Patient self-proning with high-flow nasal cannula improves oxygenation in COVID-19 pneumonia. Can J Anaesth 2020;67:1288-90.

12. Guérin C, Reignier J, Richard J-C, et al.; PROSEVA Study Group. Prone positioning in severe acute respiratory distress syndrome. N Engl J Med 2013;368:2159-68.

13. Munshi L, Sorbo LD, Adhikari NKJ, et al. Prone position for acute respiratory distress syndrome. A systematic review and meta-analysis. Ann Am Thorac Soc 2017;14(Suppl 4):S280-8.

14. Pérez-Nieto OR, Guerrero-Gutiérrez MA, Deloya-Tomas E, et al. Prone positioning combined with high-flow nasal cannula in severe noninfectious ARDS. Crit Care 2020;24:114.

15. Malinowski AK, Snelgrove J, Okun N. Excluding pregnancy from COVID-19 trials: Protection from harm or the harm of protection? CMAJ 2020;192:E634.

16. Samanta S, Samanta S, Wig J, et al. How safe is the prone position in acute respiratory distress syndrome at late pregnancy? Am J Emerg Med 2014;32:687.e1-3.

17. Tolcher MC, McKinney JR, Eppes CS, et al. Prone positioning for pregnant women with hypoxemia due to coronavirus disease 2019 (COVID-19). Obstet Gynecol 2020;136:259-61.

18. Schnettler WT, Al Ahwel Y, Suhag A. Severe acute respiratory distress syndrome in coronavirus disease 2019-infected pregnancy: obstetric and intensive care considerations. Am J Obstet Gynecol MFM 2020;2:100120.

19. Gattinoni L, Coppola S, Cressoni M, et al. COVID-19 does not lead to a "typical" acute respiratory distress syndrome. Am J Respir Crit Care Med 2020;201:1299-300.
20. Gattinoni L, Chiumello D, Caironi P, et al. COVID-19 pneumonia: Different respiratory treatments for different phenotypes? Intensive Care Med 2020;46:1099-102.

21. Ziehr DR, Alladina J, Petri CR, et al. Respiratory pathophysiology of mechanically ventilated patients with COVID-19: a cohort study. Am J Respir Crit Care Med 2020;201:1560-4

22. Ferrando C, Suarez-Sipmann F, Mellado-Artigas R, et al.; COVID-19 Spanish ICU Network. Clinical features, ventilatory management, and outcome of ARDS caused by COVID-19 are similar to other causes of ARDS. Intensive Care Med 2020 July 29 [Epub ahead of print]. doi: 10.1007/s00134-020-06192-2.

23. Alhazzani W, Møller MH, Arabi YM, et al. Surviving Sepsis Campaign: guidelines on the management of critically ill adults with coronavirus disease 2019 (COVID-19). Intensive Care Med 2020;46:854-87.

24. Coppo A, Bellani G, Winterton D, et al. Feasibility and physiological effects of prone positioning in non-intubated patients with acute respiratory failure due to COVID-19 (PRON-COVID): a prospective cohort study. Lancet Respir Med 2020;8:765-74.

25. Winearls S, Swingwood EL, Hardaker CL, et al. Early conscious prone positioning in patients with COVID-19 receiving continuous positive airway pressure: a retrospective analysis. BMJ Open Respir Res 2020;7:e000711.

26. Solverson K, Weatherald J, Parhar KKS. Tolerability and safety of awake prone positioning COVID-19 patients with severe hypoxemic respiratory failure. Can J Anaesth 2020 Aug. 14 [Epub ahead of print]. doi: 10.1007/s12630-020-01787-1.

27. Ferrando C, Mellado-Artigas R, Gea A, et al.; COVID-19 Spanish ICU Network. Awake prone positioning does not reduce the risk of intubation in COVID-19 treated with high-flow nasal oxygen therapy: a multicenter, adjusted cohort study. Crit Care 2020;24:597.

28. Zang X, Wang Q, Zhou H, et al. Efficacy of early prone position for COVID-19 patients with severe hypoxia: a single-center prospective cohort study. Intensive Care Med 2020;46:1927-9.

29. Taboada M, Rodríguez N, Riveiro V, et al. Prone positioning in awake non-ICU patients with ARDS caused by COVID-19. Anaesth Crit Care Pain Med 2020;39:581-3.

30. Taboada M, Rodríguez N, Riveiro V, et al. Short-term outcomes of 50 patients with acute respiratory distress by COVID-19 where prone positioning was used outside the ICU. J Clin Anesth 2020;67:110028.

31. Xu Q, Wang T, Qin X, et al. Early awake prone position combined with high-flow nasal oxygen therapy in severe COVID-19: a case series. Crit Care 2020;24:250.

32. Thompson AE, Ranard BL, Wei Y, et al. Prone positioning in awake, nonintubated patients with COVID-19 hypoxemic respiratory failure. JAMA Intern Med 2020 June 17 [Epub ahead of print] doi: 10.1001/jamainternmed.2020.3030.

33. Bamford P, Bentley A, Dean J, et al. ICS guidance for prone positioning of the conscious COVID patient 2020. London (UK): Intensive Care Society; 2020. Available: https://emcrit.org/wp-content/uploads/2020/04/2020-04-12-Guidance -for-conscious-proning.pdf (accessed 2020 July 12).

34. Klok FA, Kruip MJHA, van der Meer NJM, et al. Incidence of thrombotic complications in critically ill ICU patients with COVID-19. Thromb Res 2020;191:145-7.

35. Tuite AR, Fisman DN, Greer AL. Mathematical modelling of COVID-19 transmission and mitigation strategies in the population of Ontario, Canada. CMAJ 2020;192:E497-505.

36. Barrett K, Khan YA, Mac S, et al. Estimation of COVID-19-induced depletion of hospital resources in Ontario, Canada. CMAJ 2020;192:E640-6.

37. Doussot A, Ciceron F, Cerutti E, et al. Prone positioning for severe acute respiratory distress syndrome in COVID-19 patients by a dedicated team: a safe and pragmatic reallocation of medical and surgical work force in response to the outbreak. Ann Surg 2020 July 24 [Epub ahead of print]. doi: 10.1097/ SLA.0000000000004265.

\begin{abstract}
Competing interests: Michael Fralick is a Coprincipal investigator for the COVID-PRONE study (ClinicalTrials.gov no. NCT04383613). He is also is a consultant for Pine Trees Health, a start-up company developing a CRISPR-based diagnostic test for coronavirus disease 2019. Kevin Venus and Laveena Munshi are members of the steering committee of the COVID-PRONE study. No other competing interests were declared.
\end{abstract}

This article has been peer reviewed.
Affiliations: Department of Medicine (Venus, Munshi, Fralick), University of Toronto; Division of General Internal Medicine and Geriatrics (Venus), University Health Network; Interdepartmental Division of Critical Care Medicine (Munshi) and Division of General Internal Medicine and Geriatrics (Fralick), Sinai Health System, Toronto, Ont.

Contributors: All of the authors contributed to the conception and design of the work. Kevin Venus and Michael Fralick contributed to the acquisition, analysis and interpretation of data. All of the authors drafted the manuscript, revised it critically for important intellectual content, gave final approval of the version to be published and agreed to be accountable for all aspects of the work.

Funding: There was no external funding received for this work.

Acknowledgement: The authors thank Saba Manzoor for helping to create Figure 1.

Correspondence to: Michael Fralick, mike. fralick@mail.utoronto.ca 